\title{
A MODIFICATION FOR THE MAGILL CIRCUIT
}

\author{
Edward Carden, M.A., M.B., B.CHIR., F.R.C.P.(C) *
}

THE MAGILL CIRCUIT ${ }^{1}$ is a simple yet highly efficient anaesthetic breathing circuit $^{2,3}$ which is commonly used in Great Britain and Canada and in many other parts of the world. It is primarily designed for anaesthesia with spontaneous respiration although a recent publication has described a simple modification which enables it to be used for positive pressure ventilation. ${ }^{4}$ With some anaesthetic machines the position of the gas outlet makes it difficult to use the Magill circuit, because the reservoir bag is mounted too low for easy visualization or, with the circuit in place, the distance between the anaesthetic machine and the end of the operating table is so reduced that the situation is cramped for the anaesthetist.

A simple modification which can largely eliminate these two problems associated with the Magill circuit will be described here.

\section{Apparatus}

The Kenwood Gas Adaptor (Figure 1) is designed so that a completely disposable anaesthetic circle system can be mounted on one of the ports of a

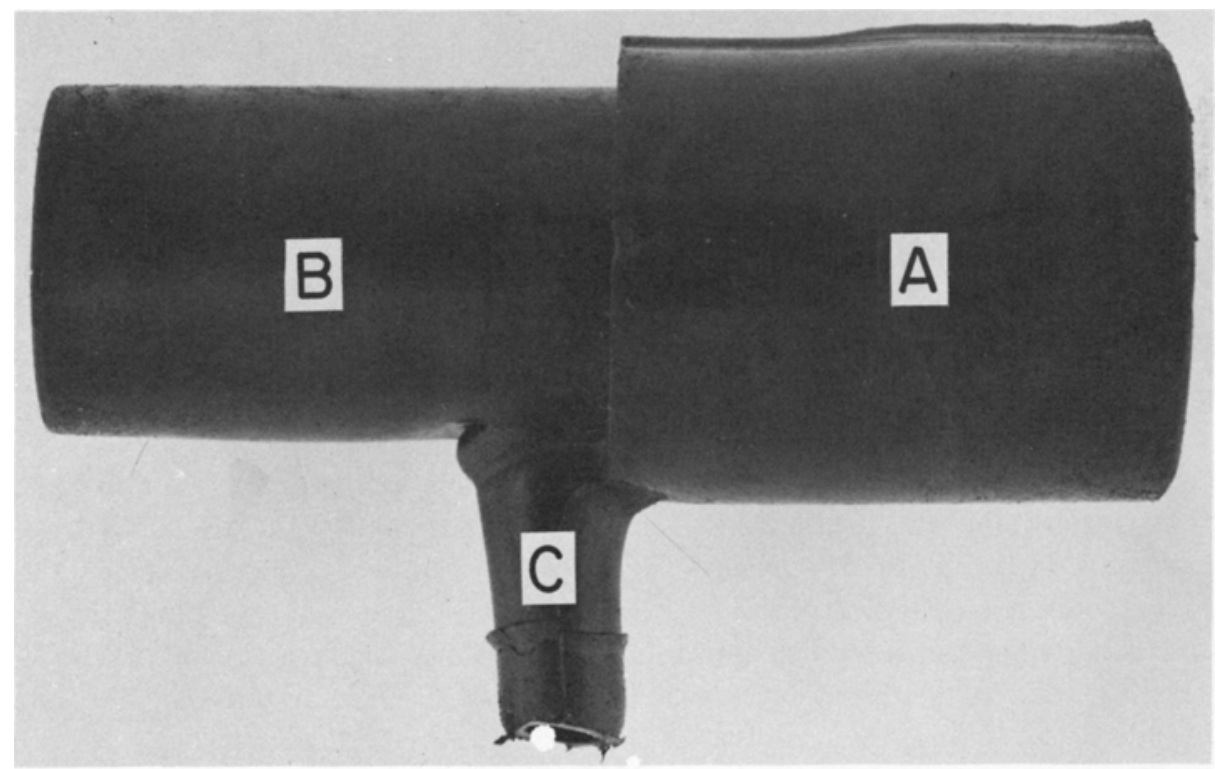

FIGURE 1. The adaptor showing (A) Connection to soda lime canister, (B) Connection to the Magill circuit, (C) Connection to fresh gas flow.

*Department of Anesthesiology, University of North Carolina, School of Medicine, Chapel Hill, North Carolina 27514, U.S.A. 


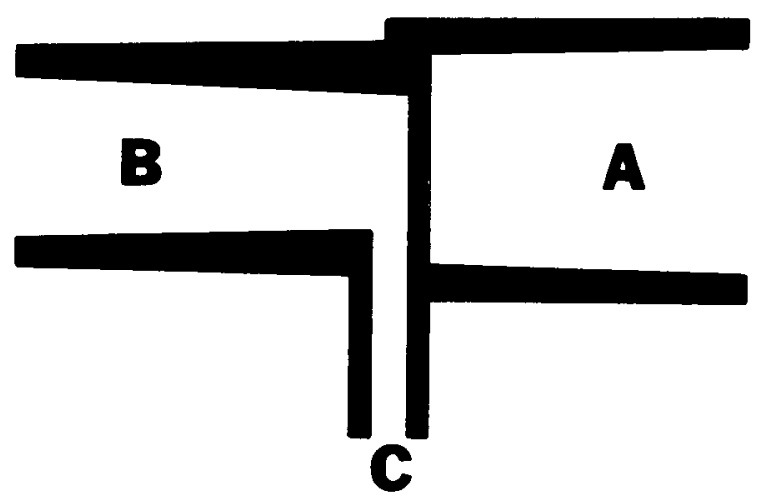

Figure 2. A schematic representation of the adaptor (not to scale) showing (A) $22 \mathrm{~mm}$ female connector, (B) $22 \mathrm{~mm}$ male connector with $15 \mathrm{~mm}$ female connector, (C) Connection to fresh gas flow.

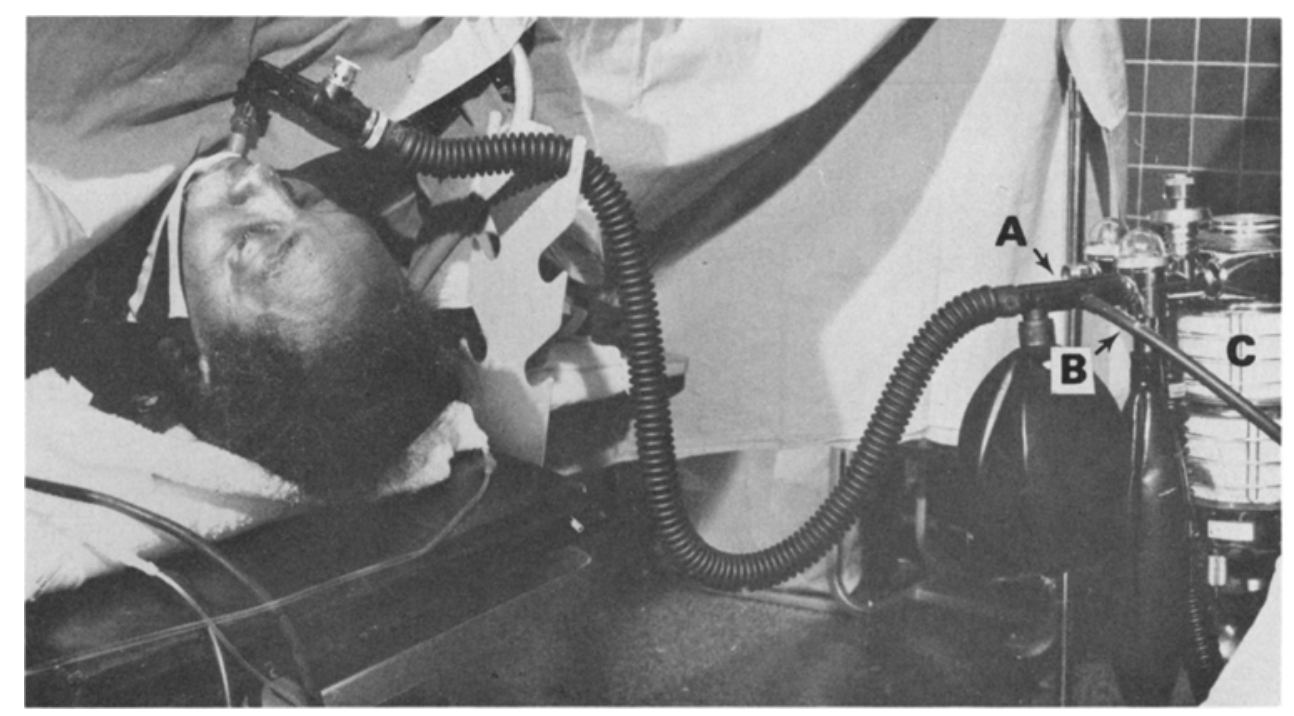

Figure 3. Showing adaptor in use. (A) Adaptor, (B) Fresh gas flow, (C) Soda lime canister.

circle-system canister. This adaptor is made of plastic and has a $22 \mathrm{~mm}$ female connector on one end and a $22 \mathrm{~mm}$ male connector, with a $15 \mathrm{~mm}$ female connector inside it, on the other end (Figure 2). The two connectors are separated by a dividing partition. A small sidearm for connection to the gas outflow of an anaesthetic machine is provided on the $22 \mathrm{~mm}$ male connector.

If this adaptor is placed on one of the ports of a circle-system canister and if the small sidearm is then connected to the anaesthetic machine gas outlet, the Magill circuit can be mounted onto this adaptor and the circuit is then held higher in the air and further away from the anaesthetic machine than it would otherwise be. This allows more room for the anaesthetist and, therefore, much easier working conditions. 
We have carried out 30 anaesthetics utilizing these adaptors. Some cracking of the adaptors occurred after multiple use, but we are told by the manufacturers that this problem will be solved. In all cases the anaesthetists felt that their working conditions were greatly improved.

\section{ACKNOWLEDGMENTS}

The author wishes to acknowledge the assistance of Will Ross, Inc., 4285 Port Washington Road, Milwaukee, Wisconsin, for their assistance in supplying these adaptors for testing and to whom all inquiries should be addressed.

\section{REFERENCES}

1. MagrLl, I. Endotracheal anesthesia. Proceedings of the Royal Society of Medicine. 22: 83 (1928).

2. KaIn, M.L. \& NunN, J.S. Fresh gas economics of the Magill circuit. Anesthesiology 29: 964 (1968).

3. Norman, J. et al. Rebreathing with the Magill attachment. Anaesthesia 23: 75 (1968).

4. Carden, E. \& Nelson, D. A new and highly efficient circuit for paediatric anaesthesia. The Canadian Anaesthetists' Society Journal 19: 572 (1972). 